\title{
Learning and Experience: Aesthetics of Multimodal Texts in Higher Education
}

\author{
Juan-Daniel Ramirez \\ jdramgar@upo.es \\ Pablo de Olavide University, Spain \\ Elodia Hernández-León \\ eherleo@upo.es \\ Pablo de Olavide University, Spain
Beatriz E. Figueroa-Sandoval
bfiguero@udec.cl
Universidad de Concepción, Chile \\ Mariana Aillon-Newman \\ maillon@udec.cl \\ Universidad de Concepción, Chile
}

\begin{abstract}
This paper invites readers to reconsider the role of Art in the learning of social sciences in higher education based on the ability of the arts to promote understanding among students about their world of life.

The new pathways opened up by multimodality offer access to vast repositories of images such as Flickr (Davies, 2007; Castañeda, 2009), and museums that exhibit high quality reproductions of their art collections (Google Art Project). Furthermore, students can express themselves by combining their own images with text (multiliteracies -The New London Group, 1996; Leander, K \& Boldt, G., 2012). Multimodal literacy represents a powerful tool to observe and record of all kinds of interesting events for social science students that can be shared and debated on social media. Moreover, following John Dewey (1980) about aesthetic experience, the new form of literacy, as result of combining imagens and texts, represents an excellent way to trigger sensible and aesthetic feelings
\end{abstract}

\section{Key words}

Art, Aesthetic Experience, Higher Education, Multimodality, Multiliteracy 


\section{Introduction}

Over the past two decades, a growing body of research has examined the role of creativity in Higher Education as a stimulus to achieve greater adaptation to a changing world (Florida, 2003). Although terms such as 'talent' or 'imagination', which make the development of creative actions possible, are present in this literature, the same is not always true of the word 'art, a field in which the hallmark characteristics of creativity are primarily projected. It is similarly not common to see references to the aesthetic experience, traditionally associated with the activity of the artist or the contemplation of a 'artwork', and, to a lesser extent, with everyday activities that can sometimes trigger aesthetic feelings (Dewey, 1980).

To foster the development of creativity in Higher Education, two processes that work in conjunction with one another must be brought up to date: the application of the visual arts, in terms of promoting aesthetic experience and creating a way of understanding the facts or events studied empathetically; and the media that foster this application: new forms of literacy expressed in the concepts of 'multiliteracies' (The New London Group, 1996) and multimodality (Kress, 2005).

These reflections and the research conducted for this article are supported by the findings reached over the last four academic years through an educational innovation activity initially entitled Art and Society: Multimodal Social Science Workshop, but which was renamed Art, Technology and Society:... in 2014-2015, conducted with students of Social Work, Sociology and Social Education.

The general idea set out in this article could be described in the following terms: art is key to achieving experiential knowledge of the world, along the path suggested by Pablo del Río when he proposed "... an educational reorientation that assigns art a more essential role in human development" (Río, 2004; p. 44). For the purposes of this paper, this re-assignation could move in two directions: on the one hand, as a means of 'showing' events from the world in which students live and move, through what could be termed perceptive education (Ingold, 2000), especially in a culture where the senses become more relevant (Duncum, 2004, 2012; Castañeda, 2009); and on the other hand, as a means for observing and discovering those events, articulating them narratively through multimodal tools. These two pathways converge into a single motive: achieving sensitive and aesthetic understanding of social phenomena, parallel to the paradigmatic knowledge that corresponds to the field of social sciences in which the students are being educated.

\section{a. Why Aesthetic Experience?}

The role of the arts in Education is beginning to be approached from a new angle. Hence, the narrative arts represent an excellent route for literacy and school learning, as shown by the use of oral tales within the framework of intercultural education ( $x x x x \& x x x x, 2008)$. However, to understand its educational role, we must go beyond the vision that focuses purely on artistic education and project the arts towards other areas of knowledge. In order to develop a concept of Aesthetics that can be applied to the learning processes, we must adopt a previous approach to those ideas that have remain preeminent since the Enlightenment times, those being; first, that Aesthetic feelings arise when contemplating the Artwork and second, the differentiation stablished by Kant between what is beautiful and what is sublime (Kant, 2015). It is also necessary to recognise the different factors that make up the 'artistic' realm and to see the mutual interdependence between them, because art as an activity that is differentiated from other activities (playing, learning, working, etc.), with its final result, the artwork, is one thing, 
and the aesthetic experience is another thing: a special psychic state differentiated from everyday experience (Marković, 2012), with which it is nonetheless related.

A more intense focus on the contemplated object, with the impression that it transcends time and space, with the added sensation that, although familiar, that object has become strange to the observer (estrangement), in addition to changes in the emotional state: these are a few of the characteristic traits of the aesthetic experience (Marković, 2012). However, the most diverse studies from philosophy to the psychology of art and neuro-aesthetics focus on contemplating works of art without outlining the possible relationship between everyday life and aesthetic experiences. Furthermore, attention has not been paid to the possibility of deriving any kind of similar feeling in activities that people carry out in their daily life; a question that in the past was tackled from the perspective of Pragmatism with a markedly evolutionist approach (Dewey, 1934/1980; Shusterman, 2000).

Dewey argued in the 1930s that the aesthetic experience not only relates to the contemplation of a work of art, in the way it has been traditionally understood, but is also 'a celebration of everyday experience' or an 'enjoyment of the everyday' (Dewey, 1980; p. 11). When a problematic situation is experienced, if the actions undertaken with a view to overcoming the state of disorder and imbalance culminate in the resolution of the problem, the equilibrium that is regained translates into "an inner feeling of harmony" (Dewey, op. cit.; p. 15). As indicated by Dewey in this regard:

"Because the actual world, that in which we live, is a combination of movement and culmination, o breaks and re-unions, the experience of a living creature is capable of aesthetic quality. The live being recurrently loses and reëstablishes equilibrium with his surroundings. The moment of the passage from disturbance into harmony is that of intense life. In a finished world, sleep and waking could not be distinguished. In one wholly perturbed, conditions could not even be struggled with. In a world made after the pattern of ours, moments of fulfilment punctuate experiences with rhythmically enjoyed intervals" (ibid; p. 17).

In contrast to the psychogenetic position, in which regaining equilibrium represents a strictly cognitive resolution of a problem, in Dewey's conception, resolution involves human sensitivity as experiential totality. His vision is closer to Vygotsky's concept of perezhivanie through the conjunction of the sensory, the cognitive and the emotional in human activity (Mahn, 2012; Vygotsky, 1993, 2004), and, to 'peak experience' (Maslow, 1964) or, more recently, to the 'key learning experience', which brings it into the realm of education (Valdés, Coll \& Fasafi, 2016). All these notions point us towards a sensation of timelessness accompanied by a feeling of wellbeing and self-recognition, with greater emphasis on the aesthetic feeling. This harmony is achieved because successive adjustments to the environment transcend the merely cognitive plane and mobilise sensitivity. If, as indicated by Dewey, in all activity (intellectual, working, etc.), the culmination of a task fosters within the executor of that task some kind of aesthetic quality or feeling, in any artistic activity, this feeling is the end pursued by the creator; hence, traditionally, critics and theoreticians are more likely to focus on the work of art rather than the activity that makes it possible.

Through their work, creators seek to mobilise the sensitivity of a spectator in particular, or a community of spectators, thus fulfilling Vygotsky's proposal: art as the social technique of feeling (Vygotsky, 1972). However, even though the activity developed in other practices is not solely and exclusively artistic, attention to form and detail are also present in other diverse spheres such as design, advertising, participation in social media through the uploading of images, etc., making it increasingly difficult to distinguish between artistic activities and other 
activities geared towards practicality. Someone who decorates their home or hopes to prepare a good meal to celebrate with family or friends feels the final result of their actions aesthetically. There are reasons to think that, sooner or later, education will also include among its intended outcomes aesthetic dimensions that are currently being neglected.

In terms of the goals of the Social Sciences Multimodal Workshop, as well as the research generated, it is important to indicate the following: if aesthetic experience is realised in the resolution of one of the many tasks indicated previously, one might logically think that these objectives will be achieved in an activity such as that developed in said workshop, in which students are invited to work multimodally. When a student photographs a subject that inspires them and writes a text based on the image obtained, their sensitivity is manifested throughout the critical moments of the task.

\section{b. Multimodality and social media}

The social web provides users with channels that can bring them closer to the most varied artistic expressions (narratives, images, videos, etc.). ICTs, given their immense multimodal possibilities, open up pathways to incorporate the visual arts in all their dimensions: cult, popular, and mutual hybrids (García Canclini, 1989), the art produced by renowned artists, by amateurs, or by social media users when they 'post' photos of their daily life (selfies, landscapes, friends and family, etc.). For the purposes of this research, the term amateur includes students of social sciences if they are invited to use their digital cameras or smartphones to record everyday events and learn to observe their surrounding reality in this way.

Everything can be transformed into the subject of observation for the social researcher when they use their imagination, which could be recognised as a sociological imagination (Mill, 1959/1999), and they position themselves at a distance from the world that surrounds them. Through the social web, as well as getting to know the different artistic manifestations, students find a way to observe, record and understand their most immediate world in which their everyday life takes place, and distant worlds, to which they have access through the media. Landscapes, cities, museums of the world, photographs of anonymous people, objects, etc., open up to the attentive observer, who develops his or her curiosity when faced with the unknown and the far removed (Google Art Project, Flickr, Instagram, etc.).

This workshop would not have been viable without the different multimedia tools, from computers to smartphones. The activity itself can be included within the framework of multiliteracies (New London Group, 1996), although the authors of this paper prefer to use the less popularised term of multimodal literacy (Hodge \& Kress, 1988; Kress, 2005; Kress \& Leewen, 2001; Lauer, 2009), since all production is the combination of materials that include at least two semiotic modalities: image and written text. An image can illustrate a text and, at the same time, inspire its writing. A photograph taken by a student becomes a motive to write. In turn, a written text sharpens their capacity for observation and leads them to capture other images of events, related or otherwise, which can then inspire new texts. The sequence of photos taken by students on the multimodal workshop and uploaded to the social medium Flickr, with footnote descriptions and the comments they leave, represent a kind of assembly (Leander \& Boldt, 2012): images and writing generate a mode of sensitive and aesthetic knowledge without the direction imposed by the regulated programme of each academic subject. 
Without wishing to disparage the model of academic literacy, dominant in the world of AngloSaxon universities, multimodal literacy can represent a very valuable instrument capable of supporting various higher education practices, for the following reasons:

- Through images, it is possible to generate a sensitive and aesthetic experience that supports the construction of knowledge.

- Images shown on a computer screen or a tablet, as well as events recorded on the camera of a smartphone, represent a valuable medium for learning to observe the world and sharing the world of other observers through social media.

- Images represent a stimulus to write about events observed, since they encourage textual production. Together, image and text construct a complex semiotic that involves both planes of understanding (cognition and emotion) and create motives to investigate and learn.

\section{c. Image + text: A semiotic description}

Which steps are taken by each participant in the multimodal workshop activity and how can the semiotic process involved in the construction of meaning be explained?

The semiologist Charles Sanders Peirce proposed understanding meaning as a process distributed into three interacting terms: Object, Sign and Interpretant (Peirce, 1987, Levinson, 1983). Inspired by this trichotomy, the researchers of this paper set out the following steps: "Object", "Subject" and "Interpretation".

Object or Subject: This is the trigger for the loop of signification. An observer is drawn to something (things, people, landscapes, etc.) and decides to photograph it. The observer adopts a certain perspective, positions their body, angles their gaze towards the object of interest, seeking an interplay of shadow and light, focusing their camera on the complete object or one of its parts, etc.

Sign or Representation. The image obtained by the observer is the medium of representation. Observers-cum-photographers, generally users of smartphones, can incorporate artistic values into the subject recorded by touching up the photograph using the filters available through their smartphone or from social media (such as Instagram).

In addition to the decisions made by the observer, reality also plays other roles. The point of view of the spectator is conditioned by the connotative meaning closely related to his or her culture, ideology and/or religious orientations, etc. (Barthers, 2001). Besides, the raw event recorded in the frame of an image can offer novelties for the spectator and even for the photographer when assuming the role of spectator. Despite the steps indicated above (perspective adopted by the photographer, processing of the images through filters, etc.), reality sometimes surprises the observer, leading him or her on occasions to modify the final text that concludes the process of interpretation. It is often the case that a photograph reveals things that were not part of the photographer's intention when taking it at first.

As Collier indicates in this regard:

[...] any visual image that is the product of pointing a camera at the world also contains all the optically visible aspect of that world within the confines of the frame and the capabilities of lens. This visual field usually contains a complex rnge of phenomena, much of which is outside our awareness as camera person or subject. Consequently, the content of the visual image is rarely shaped only by the constructive influence of recorders and subjects, a fact reflected in the process of visual analysis (Collier, 2008; p. 35) 
On the one hand, we have the subjectivity that is felt at the moment of focusing the camera or touching up the photograph, but on the other, when looking at the image obtained, the observer often sees details that they did not notice at the time. In the next step in the loop of signification, these two aspects converge.

Interpretation. When the photographer analyses the material recorded, this marks the start of a series of enquiries aimed at grasping the meaning contained in the photographed subject. When contemplating the image (representation), the observer has to write their impressions, develop a narrative or some type of plot or argument about it. In this last stage, the result is, consequently, discursive: an exercise in multimodal writing that emerges through the assembly of image and text, which broadens the capacity to generate meanings and make sense of what has been apprehended (Davies, 2007; The New London Group, 1996; Leander \& Boldt, 2012).

\section{d. Why should this be applied to social sciences?}

Using the language of Gestalt psychology, the information contained in an academic subject, or a subject or object of knowledge, is above all a figure placed against a background of information, knowledge and experiences on a broader spectrum (Ramírez \& Hernández-León, 2010). A background overshadowed by the figure onto which we have focused all our attention. A figure that has the form of a written text in which a certain theory is expounded. The background, completely ignored by the actors of higher education, is the weltanschauung, the way in which we conceive the world in its broadest sense (Ramírez and Hernández-León, 2010). This background comprises heteroclite materials, ostensibly disconnected from one another, but linked by systems of beliefs, opinions and mentalities of a certain period in time or a certain group or ethnicity. Over the past two decades, this background has incorporated the information that is displaced horizontally through the web 2.0, as the result of various interactions between its users and enquiries on the most varied pages and repositories.

No pedagogical project aimed at educating in the social sciences can be complete without seeking a fit between 'scientific explanation' and 'sensitive understanding' (empathetic and aesthetic) of the studied events or facts. Learning to capture everyday life is as important as understanding any sociological, anthropological or psychological theory. It could be added that, without this first capacity for observation and sensitive appropriation of the world, theoretical knowledge would be confined to an academic artifice that can only be understood in a closed context.

This is reminiscent of Vygotsky's criticism of verbalism, prevalent in the educational programmes of his time:

"No less than experimental research, pedagogical experience demonstrates that direct instruction in concepts is impossible. It is pedagogically fruitless. The teacher who attempts to use this approach achieves nothing but a mindless learning of words, an empty verbalism that simulates or imitates the presence of concepts in the child" (Vygotsky, 1993; p. 185).

And, if it is not possible to learn scientific concepts without harnessing personal experience in the case of children, for the same reasons, social and cultural theories taught in university contexts cannot be understood without a 'felt' understanding of the events that take place in the real world. Although the pre-conceptual structure of symbolic-narrative thought and the logical structure of theoretical and paradigmatic thought represent two different forms of knowledge (Bruner, 1988, 1991), it is nonetheless true that they can both collaborate in the training of 
sociologists and educators: the first, by generating a sensitive appropriation of social events; the second, by promoting an explanation based on analytical rigour. The aim, therefore, would be to develop a model of knowledge capable of overcoming what del Río, following Vygotsky, called a "psychology without space", in which the visual and the spatial have been devoured by the verbal and propositional (Río, 2004; p. 47).

This leads us to consider activity linked to art for two reasons: firstly because, based on personal experience, recorded in an image or developed textually, the author transforms this autobiographical experience into an aesthetic experience (Dewey, 1980); and secondly, because the photograph and the accompanying narrative create a distancing effect in relation to the event or characters recorded, an effect that is equal parts art and social science.

\section{e. Three objectives and a motive}

Over the course of the Social Sciences Multimodal Workshop, there were three objectives pursued and one motive that permeates the entire activity:

1. Perceptive education. Learning to look and observe the world.

2. Reasoning and thinking through multimodal writing.

3. Sharing the experience recorded in the multimodal text with their class, both face-to-face (classroom) and virtually (Flickr, Google+).

The central motive is the development of the capacity to feel aesthetically the events observed in the real life world.

The aesthetic meaning must not be seen as an objective to be achieved but rather as a motive that emerges and develops through the actions that make up the activity (Burke, 1969). An artist carries out their work, seeking to experience what they do aesthetically and to convey this experience to be shared by the public. Students are guided towards carrying out this task with learning as the goal. This is the most notable difference between John Dewey's perspective and traditional theories focused on the work of art. As in so many activities of everyday life, the aesthetic is not the ultimate aim; rather it is found over the course of the activity.

\section{Methodology}

As the experience developed in the Multimodal Workshop of Social Sciences involves the production of multimodal texts, qualitative methodology is the most appropriated for the analysis of images and writing discourses in mutual interdependence. The approach followed by the participants in the workshop shares with the photovoice methodology (Sutton-Brown, 2014) the interest to empower the students in their process of learning, trusting in their abilities to observe the surrounding world and make meaning to their personal and critical role in it.

In this paper the main interest is to create analytical categories that lets understand the "theme" of each photography and the (writing) discourse inspired in it. This level analysis will be the ground on which to develop more complex forms of understanding of the interaction between imagen and discourse. 


\section{a. Description of the experience}

The Social Sciences Multimodal Workshop is run as part of the academic subjects 'Introduction to Social Anthropology' and 'Introduction to Human Psychological Functioning' taught on the first year of the degree in Social Education. It is also developed within the optional subjects 'Cognitive Foundations of Communication' (fourth year of the degree in Sociology) and 'Social Interaction and Communication' (fourth year of the degree in Social Work). The same experience is developed in the Faculty of Education during the last two academic course by Professors Figueroa-Sandoval y Aillon-Newman. In the present paper the multimodal texts studied in this article correspond to the fourth-year subjects in Social Work and Sociology.

The entire experience revolves around the social medium Flickr. In the first class, the teacher provided the group name, 'imagination', and the students had to complete it. Hence, the full names of each group were as follows:

Sociological Imagination

(https://www.flickr.com/groups/2081808@N25/)

Imagination without borders I

(www.flickr.com/groups/2155826@N20/)

Imagination without borders II

(https://www.flickr.com/groups/2557316@N23/)

The first group was made up of fourth-year students studying a degree in Sociology and the other two groups of students were from two different year groups studying a degree in Social Work. The experiment conducted with Sociology students has continued into the current academic year, except that the subject is now being taught in English, which is why the findings obtained will be analysed in future studies.

Using cameras or smartphones, students should take pictures letting go of themselves by what motives or inspires them from the context surrounding them. Photographs could be taken, either by following a plan (students could have programmed a "theme" for the photograph) or just by taking a spontaneous photo of something that catches their attention instantaneously.

The first two photographs were provided by the teacher (two black and white panoramic photos of a beach with tourists). At the foot of the first photograph, there was the title and a window with text commenting on a quotation by Ortega y Gasset taken from his book The Revolt of the Masses (https://flic.kr/p/dntmv2).

Each photograph had to be accompanied by a title and a written text. Although no limitations were imposed whatsoever, students were invited to write as extensively as possible, in order to exercise their writing.

During the first 30 or 45 minutes of each two-hour class, students logged onto their Flickr group and commented on the photographs and texts included from the previous class. Discussion was also encouraged.

Finally, the participants in the activity were asked to produce two multimodal texts (photograph+writing). Once all the participants had included their two productions, they could continue to upload further images if they wished.

Although qualitative methodology was used, the inclusion of a few percentages should give an idea of the thematic distribution of the material obtained. 
Over the course of three consecutive years of work carried out in the Multimodal Workshop, 114 final-year students from the Sociology and Social Education degree courses graduated. Given that some were unable to participate in the workshop in person because of work commitments or because it clashed with other activities (such as external placements), a total of 122 photographs were submitted (two per participant), of which 93 were analysed $(76.22 \%)$ since those that were not accompanied by a written text were discarded.

\section{b. Category of analysis for images}

Firstly, the photographs were distributed into two broad-spectrum categories: "Landscapes" and "People". The first was further divided into two sub-categories ("Natural landscapes" and "Urban landscapes") and the second into the sub-categories of: Bonds of Affection and Unknown people.

The subcategory of "Natural Landscapes" included images that, in some cases, excluded people entirely, whereas in others, the presence of an individual or small group was so far from the camera that the focus of attention was on the natural environment.

As in the previous case, "Urban Landscapes" might record the presence of an individual or group (Unknown people), although they were not the photographer's focus of attention. Empty "Urban Landscapes" generally included streets, squares or parks, in which the photographer avoided capturing any human presence. But this category also featured interior spaces (escalators, the corridor of a public space, a classroom, etc.).

In the case of natural and urban spaces, the photograph should show that the landscape was the central theme and subject, and that any human figures captured in the photograph were unrecognisable given the distance from the camera. This criterion was adopted based on Gestalt Theory about figure-background contrast (Arnheim, 2005).

As for the second category ("People"), which included the presence of specific people who were objects of interest for the photographer and observer ("Bonds of Affection" and "Unknown People"), the proxemic features of the image captured determined the difference between the two subcategories (Bell, 2008). In the first case, this subcategory included images of family members or close friends. The close-up or proximity of the camera to the character or the group is the most distinctive trait. The proximity and physical contact show the level of intimacy of the photographed group. As for the category Unknown People, it should be noted that there is no overlap with the category Urban Landscapes, since the image reflects individuals with whom direct contact has been made in a public place. Given the photographer's interest and emphasis on a single person, it is more realistic to group these photographs in their own category. The best demonstration of this subcategory can be found in the photograph of a beggar with his dog, since the student made direct contact with him to find out about his situation and life. Having described some of the factors present in the analysis of images, this next section will examine the multimodal text as a totality (image + writing).

\section{c. Analysis of multimodal text (image + text)}

At the plane of discourse analysis researchers find two forms of multimodal discourse: the first is a discourse centred on an individual's own experience (Personal experiences) and hence presents an eminently narrative structure; whereas the second is a Hybrid discourse, a combination of autobiography and academic argumentation which has already been found in 
studies on literacy in adults, albeit with a higher level of semantic complexity (Ramírez, 1995; Ramírez \& Wertsch, 1997; Sánchez-Medina, Ramírez \& Martínez, 1998).

\section{Results}

\section{a. Analysis of Images}

"Natural landscapes" represented $27 \%$ of all the photographs. Some of the images excluded people (17.20\%), whereas others included people and small groups (for example, hikers) located far from the camera; hence the focus of attention or subject of the photograph was the landscape itself (9.67\%).

"Urban landscapes" were of interest to a larger proportion of the students (42\%). As in the previous case, these might include people (24.7\%) or not $(17.20 \%)$.

As for the category "People", the following results were found:

The subcategory "Bonds of Affection" included images of family members as well as close friends (16.12\%). Proximity and physical contact show the intimacy of the photographed group. The fact that the majority of the subjects photographed are looking directly at the camera is another of the salient features.

"Unknown People" (11\%) included contacts made for the first time or on very few occasions with someone in particular who, for some reason, is no longer anonymous to the observer.

\section{b. Discursive positioning (author/audience relationship)}

Before analysing the written texts, it is interesting to examine the discursive positioning of the student with regard to the potential audience.

Although these multimodal texts are included on an open social medium (Flickr), almost all members of the group establish an explicit discursive bond with their closest audience, their class group, as shown in the following cases:

$A D$, in the text, "Tunisia,... Changing perception", describes her experience in another country, directly addressing her fellow classmates:

"Hi guys, I took this photo in September 2012 on my trip to Tunisia ...".

AT ("The Authority") argues the role of the police in demonstrations based on a photograph taken from the web:

"I'm sure that many of you have seen these kinds of images over the past few weeks...".

There is an explicit relationship between author and audience established when the first author greets and addresses her classmates, who are also present in the discourse ("Hi there guys...", "...many of you..."). The author of the photograph and written text becomes present through the first person form of the verb ("I took", "I'm sure" or "I have the pleasure"); hence, in spite of the 'open' character of the web, it is clear that the I-speaker utters a discourse aimed at a specific audience: the student's class group. In light of discursive pragmatics, it could be said that there is not much difference between what happens in this situation linked to social media and what happens in other forms of everyday discourse (Levinson, 1983; Kerbrat Orecchioni, 1986). 


\section{c. Discourse centred on autobiographical experiences}

In this type of discourse, the writing evoked by the image focuses on the Self, on an experience from the author's recent or distant past with an emotional content, as seen in the following examples. The excerpts of texts presented below provide clear demonstrations of emotional expressivity. This becomes clear in the photographs of empty natural landscapes. These are texts dominated by lyricism, nostalgia for a lost childhood, or self-discovery. This is true in the case of $\mathrm{M}$, entitled Lost nature:

M.: '[...] Just looking at the undergrowth, weeds growing in the damp soil after the winter rains, brings back memories, nostalgia for a childhood filled with life, filled with imagination, running over the green earth as I made up children's games whilst stretched out on the sunny or damp undergrowth.

(https://www.flickr.com/photos/94222886@N08/8602461071/in/pool-2155826@N20).

In the category presented in the study of images entitled Bonds of Affection, the texts reflect strong attachment to the family, relative, or friends.

In the multimodal text by MJP, entitled My family, the author focuses on the bonds of affection she has with her circle of closest friends, who she sees as a continuation of her family setting, as her main source of support during her years at university.

MJP.: 'I have posted this photo because this is my little family, one of the best things university has given me personally; I've had some incredible times, they have taught me so much, and they have been with me during every sad and happy moment [...]' (https://www.flickr.com/photos/118276465@N07/14005323695/in/pool-2557316@N23/)

The different texts written in relation to the categories indicated above are narratives that are circumscribed to close personal experiences (natural landscapes) or people with whom the author has a close personal relationship. But does this mean that only autobiographical experience has a place in the workshop's multimodal activities and that the subjects of social sciences are excluded? If so, the multimodal workshop would be just like any literary workshop although with the novel introduction of the image as a subject.

\section{d. Hybrid discourse}

The second category of analysis, "Hybrid Discourse", presents a dual structure: the author begins with the manifestation of a personal experience similar to the previous multimodal discourses, before moving onto an argument, a subject developed in class or by social sciences in general.

This is the case of FRL, who, based on a photograph in which two girls are hugging in an airport, develops an interesting reflection about the theory of 'non-places' defended by social anthropologist Marc Augé, studied and debated in class and through other subjects on the programme.

FRL.: 'I would like to share this photo because in class we have been talking about nonplaces. This photo is in an airport, welcoming back my best friend after seven years not seeing one another. This re-encounter happened in a 'non-place', which for us became a 'place', because we will never forget that long-awaited meeting at Ibiza airport.... We cried, we laughed, we wanted to say so much and we didn't know where to start. We started by having a coffee in that non-place that for us became a very important place' (https://www.flickr.com/photos/120084284@N07/13931159332/in/pool-2557316@N23/).

We find something very similar in a photograph uploaded by $X$, showing her mother reading. With this image, which is very good technically - in which her mother, lying back, and the book 
are cast in shadow - the author establishes a relationship between this image and reading as a conquest in the process of female emancipation.

X.: '[...] Another thing I wanted to mention is the book that my mother was given, Women who read are dangerous, by the author Stefan Bollmann. It could be called a 'Sociological' book. It features old and new paintings of women reading books, notebooks, letters [...] I think it's very interesting, but even more so I love the image in history of women absorbed in reading. An educated woman doing away with the stigma entrenched in society of the "little wife" with no education. Devoted to her family and children [...] It's nice, that was how it began to gain ground gradually over time, something that has not yet been fully accepted: equality'.

(https://www.flickr.com/photos/89096006@N05/8280323571/in/pool-2081808@N25/)

The most distinctive trait can be found in the interrelation between autobiographical experience (focusing on oneself) and the social and cultural theories the participants have been studying since the start of their degree courses. This is reflected, in the first case, in the meeting with a close friend framed within the impersonal space of an airport, understood as a 'non-place'. In the second case, it is the reading woman and the emancipation of women, whose conquests include accessing reading as an activity linked to leisure and other spheres of culture.

This convergence between autobiographical experience and subjects of theoretical interest was present in $16 \%$ of the multimodal texts produced. Aspects such as cultural identities, interculturality, gender, religiousness, etc., provided motives to write, although in all cases, these subjects came in contact with a personal experience in which to anchor their discourses.

\section{Conclusion and final reflections}

The main findings reached in this research derived from the Social Sciences Multimodal Workshop innovation experiment point to certain conclusions that could feed into future pedagogical experiments developed within the framework of Higher Education.

It is important to trust students' capacity for observation, for feeling and perceiving their environment, in order to connect learning and their autobiographical experiences. These experiences have led to the creation of images that allow them to develop intuitive knowledge in which they can ground the abstract concepts of social sciences.

The capacity to capture an experience in a photographic image and transform it into a narrative, an essay, etc., promotes a new form of multimodal writing through which experiences can be shared within a social medium.

Multimodal literacy requires the development of a methodology capable of approaching a form of textuality understood as the complex made up of the image and written text, notwithstanding the potential future incorporation of new forms of modality (for example, music).

Finally, in response to the question about the way in which aesthetic experience emerges, it is important to remember the objectives of the multimodal workshop and indicate that the task does not promote a merely contemplative experience, as occurs with audience members watching a play or visitors to a museum. In this activity, the objectives are educational ('learning to look', 'developing multimodal writing' and 'acting as part of a network'); hence the aesthetic experience is not an aim in itself; but rather the expectation is that it will emerge 
over the course of the different actions undertaken (observe, photograph, write, discuss with fellow classmates, etc.); hence its status as a motive that emerges and is developed over the course of the activity.

Future research channelled in this and other complementary directions will allow researchers to re-evaluate a mode of understanding and knowledge based on the experiences of students, which will complement theoretical knowledge characteristic of the diverse paradigms that make up the complex puzzle of social sciences.

\section{Acknowledgements}

This research has been conducted within the Innovation and Teaching Development Plan of Universidad Pablo de Olavide, Seville. It is part of the Action 2 programme: "Projects aimed at the design and application of new teaching and assessment methodologies, focusing primarily on training in competencies".

\section{References}

Arnheim, R. (2005). Arte y percepción visual. Madrid: Alianza.

Barthes, R. (2001). Rhetoric of the image. Evans, J. \& Hall, S. (ed.). Visual culture: the reader. (pp. 33-40) London, UK: SAGE.

Bruner, J. (1988). Realidades mentales y mundos posibles. Barcelona: Gedisa.

Burke, K. (1969). A Grammar of Motives. Berkeley and Los Angeles, CA: Universsity of California Press.

Castañeda, I. (2009). Visual Culture, Art History and the Humanities. Arts \& Humanities in Higher Education. 8, 41-55 (doi:10.1177/1474022208098301).

Dewey, J. (1980). Art as Experience. New York: Perigee.

Duncum, P. (2012). An Eye Does Not Make an I: Expanding the Sensorium. Studies in Art Education. 53, 182-193 (doi:10.1080/00393541.2012.11518862).

Duncum, P. (2004). Visual Culture Isn't Just Visual: Multiliteracy, Multimodality and Meaning. Studies in Art Education. 45, 252-264 (doi:10.1080/00393541.2004.11651771).

Florida, R. (2003). Cities and the Creative Class. City \& Community, 2, 3-19 (doi:10.1111/1540-6040.00034).

Figueroa, B. \& Aillon, M. (2008). Elaboración de un texto intercultural mapuche: Aproximaciones didácticas. Estudios Pedagógicos. 34, 93-104. (http://dx.doi.org/10.4067/S0718-07052008000100005).

García Canclini, N. (1989). Culturas híbridas. Estrategias para entrar y salir de la modernidad. México: Grijalbo.

Hodge, R. \& Kress, G. (1988). Social Semiotics. Cambridge, UK: Polity.

Ingold, T. (2000). The Perception of the Environment. London, UK: Routledge.

Kant, I. (2015). Observaciones acerca del sentimiento de lo bello y de lo sublime. Madrid: Alianza. 
Kress, G. (2005). Gains and Losses: New Forms of Texts, Knowledge, and Learning. Computer and Composition. 22, 5-22 (doi:10.1016/j.compcom.2004.12.004).

Kress, G. \& Van Leeuwen, T. (2001). Multimodal discourse: The modes and media of contemporary communication. London: Arnold

Lauer, C. (2009) Contending with Terms: "Multimodal" and "Multimedia" in the Academic and Public Spheres. Computers and Composition. 26, 225-239 (doi:10.1016/j.compcom.2009.09.001).

Leander, K \& Boldt, G. (2012). Rereading "A Pedagogy of Multiliteracies": Bodies, Texts, and Emergence. Journal of Literary Research. 20, 1-25 (doi: 10.1177/1086296X12468587).

Leeuwen, T. van (2015). Introducing Social Semiotics. New York, NY: Routledge.

Mahn, H. (2012). Vygotsky's Analysis of Children's Meaning Making Processes. International Journal of Educational Psychology. 1, 100-126. (doi: http://dx.doi.org/10.4471/ijep.2012.07).

Marković, S. (2012). Components of Aesthetic Experience: Aesthetic Fascination, Aesthetic Appraisal, and Aesthetic Emotion. I-Percetion. 3, 1-17. (http://dx.doi.org/10.1068/i0450aap).

Maslow, A. (1964). Religions, Values, and Peak Experiences. Columbos, Ohio: Ohio State University.

Peirce, C. S. (1987). Obra Lógico Semiótica. Madrid: Taurus.

Ramírez, J. D. (1995). Usos de la palabra y sus tecnologías. Buenos Aires: Miño y Dávila Editores.

Ramírez, J. D. Wertsch, (1997). Discourse in Adult Classroom. Rhetoric as Technology for Dialogue. En L. Resnick, R. Saljo, \& C. Potecorvo, \& B. Burge (Eds.). Situated Cognition and Technologycally Supported Enviroments (pp. 441-458). Berlin, Heidelberg: SpringerVerlag.

Ramírez, J. D. (2011). Humanismo, arte y educación. Lulu Coquette. Revista de didáctica de la lengua y la literatura. 6, 12-28.

Ramírez, J. D. y Hernández León, E. (2010). Cine y Sociedad: Una experiencia multimodal. Domínguez, G., López, E. y Hernández León, E. (Comps.). Seminario sobre innovación en metodologías docentes 2.0 en Educación Social (pp. 39-57). Sevilla: Edición Digital.

Río, P. del (2004). "El arte es a la vida lo que el vino es a la uva". La aproximación sociocultural a la educación artística. Cultura y Educación, 16, 43-64.

Roth, N. (2010). Writing as pretext: On the way of image. Arts and Humanities in Higher education. 9, 256-264 (Doi: 10.1177/1474022210361455).

Sánchez-Medina, J. A., Ramírez, J. D. y Martínez, V. (1998). Proceso de argumentación en situaciones cotidianas. I Jornadas de Psicología del Pensamiento (pp. 259-271). Universidad de Santiago de Compostela..

Sutton-Brown, C. A. (2014). Photovoice: A Methodological Guide. Photography \& Culture. 7 (2), 169-186. (https://doi.org/10.2752/175145214X13999922103165).

Shusterman, R. (2000). Pragmatic Aesthetic. Living, Beauty, Rethinking Art. New York: Rowman \& Littelfield. 
The New London Group (1996). A Pedagogy of Multiliteracies: Designing Social Futures. Harvard Educational Review, 66, 60-92 (doi: http://dx.doi.org/10.17763/haer.66.1.17370n67v22j160u)

Valdes, A., Coll, C. y Falsafi, L. (2016). Experiencias transformadoras que nos confieren identidad como aprendices: las experiencias claves de aprendizaje. Perfiles educativos. Vol XXXVIII, 153, 168-184.

Vygotski, L. S. (1993). Pensamiento y lenguaje. L. S. Vygotski: Obras escogidas II (pp. 9287). Madrid: Aprendizaje-Visor.

Vygotski, L. S. (2004). Extractos de los escritos sobre psicología del arte y educación creativa. Cultura y Educación, 16, 19-41.

Vygotsky, L. S. (1972). Psicología del Arte. Barcelona: Barral.

Writhg Mills, C. (1999). La imaginación sociológica. Madrid: Fondo de Cultura Económica. 